\title{
KARAKTERISTIK LINGKUNGAN PERAIRAN KEPULAUAN SERIBU
}

\author{
Oleh : Suhendar I Sachoemar \\ Badan Pengkajian dan Penerapan Teknologi (BPPT)
}

\begin{abstract}
An identification of the environment characteristics of the Seribu Islands was conducted by using the physical and chemical data obtained from various sources. The characteristics of the water quality at the Seribu Island was identified as a moderate level in the middle part and better in the northern part. While in the southern part was poor due to the effect of the degraded water quality at Jakarta Bay as indicated by low transparency and high heavy metal concentration of the $\mathrm{Cd}$ and $\mathrm{Pb}$.
\end{abstract}

Keywords : Karakteristik lingkungan perairan, Kepulauan Seribu

\section{PENDAHULUAN}

Perairan Kepulauan Seribu yang merupakan bagian dari wilayah perairan DKI Jakarta terletak di sebelah luar perairan Teluk Jakarta. Perairan ini secara oseanografis cukup rentan terhadap berbagai ancaman pencemaran, mengingat lokasinya berhubungan langsung dengan Teluk Jakarta tempat bermuaranya 13 sungai yang melintasi Kota Jakarta yang padat pemukiman dan industri 1). Secara geografis, perairan Kepulauan Seribu memiliki peran penting dan signifikan terhadap pertumbuhan ekonomi daerah melalui pengembangan industri kelautan seperti jasa perhubungan laut, transhipment, penambangan minyak dan pariwisata.

Berbeda dengan kawasan perairan Teluk Jakarta yang disekitarnya sarat dengan dinamika pembangunan berbagai industri manufaktur, pusat perdagangan, pelabuhan dan pelayaran, perkotaan baru berbatasan laut (water-front city), pengembangan kawasan perairan Kepulauan Seribu memerlukan kebijakan yang tepat sesuai dengan karakteristik sumberdaya dan lingkungan perairannya.

\footnotetext{
Sebagai salah satu ekosistem laut di perairan utara Jakarta, wilayah perairan Kepulauan Seribu didominasi oleh ekosistem terumbu karang, padang lamun dan daratan pulau-pulau karang yang menjadi habitat penting berbagai jenis biota perairan laut ${ }^{2)}$. Pemanfaatan sumberdaya hayati laut terutama sumberdaya ikan menjadi sumber utama penghidupan sebagian besar masyarakat yang tinggal di kepulauan.
}

Sekitar $71,6 \%$ penduduk Kepulauan Seribu adalah nelayan yang menggantungkan kehidupannya pada hasil penangkapan ikan baik di dalam maupun di luar wilayah perairan Kepulauan Seribu. Ikan pelagis, ikan karang, ikan hias, dan biota laut lainnya merupakan target penangkapan para nelayan Kepulauan Seribu. Pengembangan perikanan tangkap meskipun prospektif tetapi memerlukan suatu pengelolaan yang tepat. Perkembangan terakhir mengindikasikan bahwa populasi sumberdaya ikan semakin menurun.

Penurunan ini selain disebabkan oleh penggunaan bahan peledak dan bahan kimia secara meluas untuk penangkapan ikan karang dan ikan hias, juga diduga disebabkan oleh terjadinya penurunan kualitas perairan di Kepulauan Seribu. Untuk mengetahui kondisi lingkungan perairan Kepulauan Seribu maka telah dikumpulkan beberapa data biofisika dan kimia perairan Kepulauan Seribu yang diambil dari berbagai sumber.

\section{METODE PENELITIAN}

Metode penelitian yang dilakukan dalam studi ini adalah metode survei dengan melakukan pengumpulan data biofisika dan kimia perairan baik melalui survei langsung dilapangan, maupun data sekunder dan informasi dari berbagai sumber. Data dan informasi yang dikumpulkan antara lain data geografi, geologi dan iklim.

Kemudian data oseanografi (arus, gelombang), batimetry, dan data biofisika-kimia perairan (Tabel 1). Survei lapangan dilakukan pada bulan Agustus 2004 di beberapa lokasi yang termasuk kedalam wilayah Perairan Kepulauan Seribu Bagian Selatan, Tengah dan Utara (Gambar 1). 


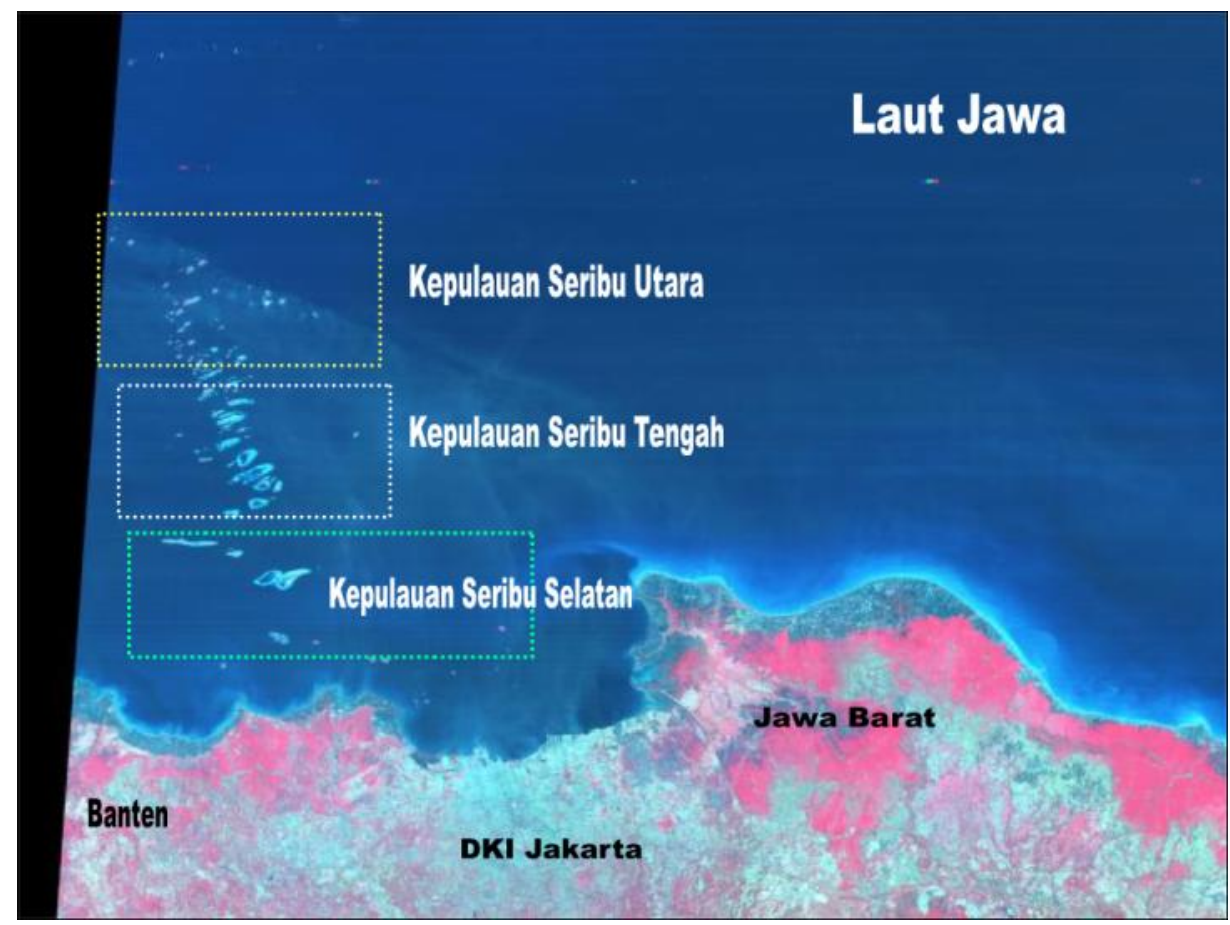

Gambar 1. Lokasi Penelitian di Perairan Kepulauan Seribu

Tabel 1. Parameter Biofisika-Kimia Lingkungan Perairan

\begin{tabular}{|l|l|l|}
\hline \multicolumn{3}{|c|}{ Parameter } \\
\hline Fisika & Kimia & Logam Berat \\
\hline Suhu $(\stackrel{\circ}{\circ} \mathrm{C})$ & $\mathrm{pH}$ & $\mathrm{Pb}(\mathrm{mg} / \mathrm{l})$ \\
\hline Salinitas $(\mathrm{ppm})$ & $\mathrm{DO}(\mathrm{mg} / \mathrm{l})$ & $\mathrm{Cu}(\mathrm{mg} / \mathrm{l})$ \\
\hline Kecerahan $(\mathrm{m})$ & BOD $(\mathrm{mg} / \mathrm{l})$ & $\mathrm{Cd}(\mathrm{mg} / \mathrm{l})$ \\
\hline Arus $(\mathrm{cm} / \mathrm{dtk})$ & COD $(\mathrm{mg} / \mathrm{l})$ & $\mathrm{Hg}(\mathrm{mg} / \mathrm{l})$ \\
\hline & Silika $(\mathrm{mg} / \mathrm{l})$ & \\
\hline & Minyak $(\mathrm{mg} / \mathrm{l})$ & \\
\hline & DIN $(\mathrm{mg} / \mathrm{l})$ & \\
\hline & Fosfat $(\mathrm{mg} / \mathrm{l})$ & \\
\hline & Ammoniak $(\mathrm{mg} / \mathrm{l})$ & \\
\hline
\end{tabular}

\section{HASIL DAN PEMBAHASAN}

\subsection{Kondisi Geografi dan Iklim}

Berdasarkan Undang-Undang Nomor: 34 Tahun 1999, Kepulauan Seribu telah ditetapkan sebagai salah satu Kabupaten Administratif setingkat dengan wilayah daerah tingkat II di Provinsi Daerah Tingkat I DKI Jakarta. Secara geografis Kabupaten Administratif Kepulauan Seribu terletak di lepas pantai utara Jakarta, berbatasan langsung dengan Laut Jawa disebelah utara, timur dan barat. Sedangkan di sebelah selatannya, berbatasan langsung dengan wilayah Kotamadya Jakarta Utara, Provinsi Banten dan Jawa Barat.
Berdasarkan Surat Keputusan Gubernur DKI Jakarta No.1986 Tahun 2000, wilayah Kepulauan Seribu terdiri dari 110 pulau yang secara administratif terbagi kedalam 6 wilayah antara lain : Kelurahan Pulau Panggang, Pulau Harapan dan Pulau Kelapa yang termasuk kedalam Kecamatan Kepulauan Seribu Utara, sedangkan di Kecamatan Kepulauan Seribu Selatan terdiri dari Kelurahan Pulau Untung Jawa, Pulau Tidung dan Pulau Pari (Gambar 2). Dari keenam kelurahan tersebut Kelurahan Pulau Kelapa memiliki pulau terbanyak yakni 36 pulau dan yang paling sedikit adalah Pulau Tidung dengan 6 pulau ${ }^{5), 6}$. 
Kabupaten Administrasi Kepulauan Seribu memiliki luas wilayah sekitar $1.180,80$ ha yang terdiri dari wilayah perairan dengan luas sekitar $6.997,5 \mathrm{~km}^{2}$ dan gugusan pulau-pulau yang tidak berpenghuni dan berpenghuni seluas kurang lebih 869,71 ha. Pulau-pulau di Kepulauan Seribu relatif tidak terlalu luas. Pulau Tidung Besar dengan luas 50 ha merupakan pulau terbesar di Kepulauan Seribu, kemudian Pulau Payung Besar 20 ha, Pulau Kotok Besar 20 ha, Pulau Sebaru Besar 37 ha dan Pulau Bira Besar 29 ha. Penyebaran pulau di Kepulauan Seribu relatif tidak merata.

Berdasarkan sebarannya, gugusan pulau di Kepulauan Seribu dapat dikelompokkan kedalam dua kelompok. Kelompok pertama terdiri dari gugusan Kepulauan Seribu Utara dengan sebaran pulau-pulaunya yang cukup rapat mulai dari Pulau Peteloran di ujung utara sampai dengan Pulau Karang Besar. Kelompok kedua adalah gugusan Kepulauan Seribu Selatan dengan sebaran pulaunya yang cukup berjauhan yaitu mulai dari Pulau Tidung Besar sampai dengan Teluk Jakarta termasuk pulau yang paling terpencil di Teluk Jakarta yaitu Pulau Sabira (Gambar 3).

Kondisi angin di Kepulauan Seribu sangat dipengaruhi angin monsoon yaitu Angin Musim Barat (Desember-Maret) dan Angin Musim Timur (Juni-September). Musim Pancaroba terjadi antara bulan April-Mei dan Oktober-November. Kecepatan angin pada musim Barat bervariasi antara 7-20 knot/jam dan bertiup dari barat daya sampai barat laut. Angin kencang dengan kecepatan 20 knot/jam biasanya terjadi antara bulan Desember-Februari.

Pada musim Timur kecepatan angin berkisar 7-15 knot/jam yang bertiup dari arah Timur sampai Tenggara. Musim basah di Kepulauan Seribu mencapai maksimum pada bulan Januari, sedangkan musim kering mencapai puncaknya pada bulan Juli sampai dengan Agustus. Tipe iklim di Kepulauan Seribu termasuk tropika panas dengan suhu maksimum $32,3^{\circ} \mathrm{C}$, suhu minimum $21,6^{\circ} \mathrm{C}$ dan suhu ratarata $27^{\circ} \mathrm{C}$ serta kelembaban udara $80 \mathrm{~mm} \mathrm{Hg}{ }^{7}$.

Kondisi perairan Kepulauan Seribu dipengaruhi musim, pada musim timur tinggi gelombang lebih rendah dibandingkan dengan musim barat yaitu masing-masing berkisar antara $0,5-1 \mathrm{~m}$ dan $2-3 \mathrm{~m}$. Kecepatan gelombang rata-rata di perairan Kepulauan Seribu relatif rendah yaitu hanya mencapai 1 knot. Kondisi ini terjadi sebagai akibat dari adanya proses peredaman gelombang oleh gugusan pulau yang berserakan di perairan Kepulauan Seribu. Pengukuran di Pulau Pramuka mencatat tinggi gelombang rata-rata sebesar 7,0-69,6 cm dengan periode gelombang 2,4-6,3 detik. Gelombang di daerah tubir akan lebih besar dibandingkan gelombang di kawasan pantai. Oleh karena di pantai terjadi peredaman gelombang oleh rataan karang dangkal.

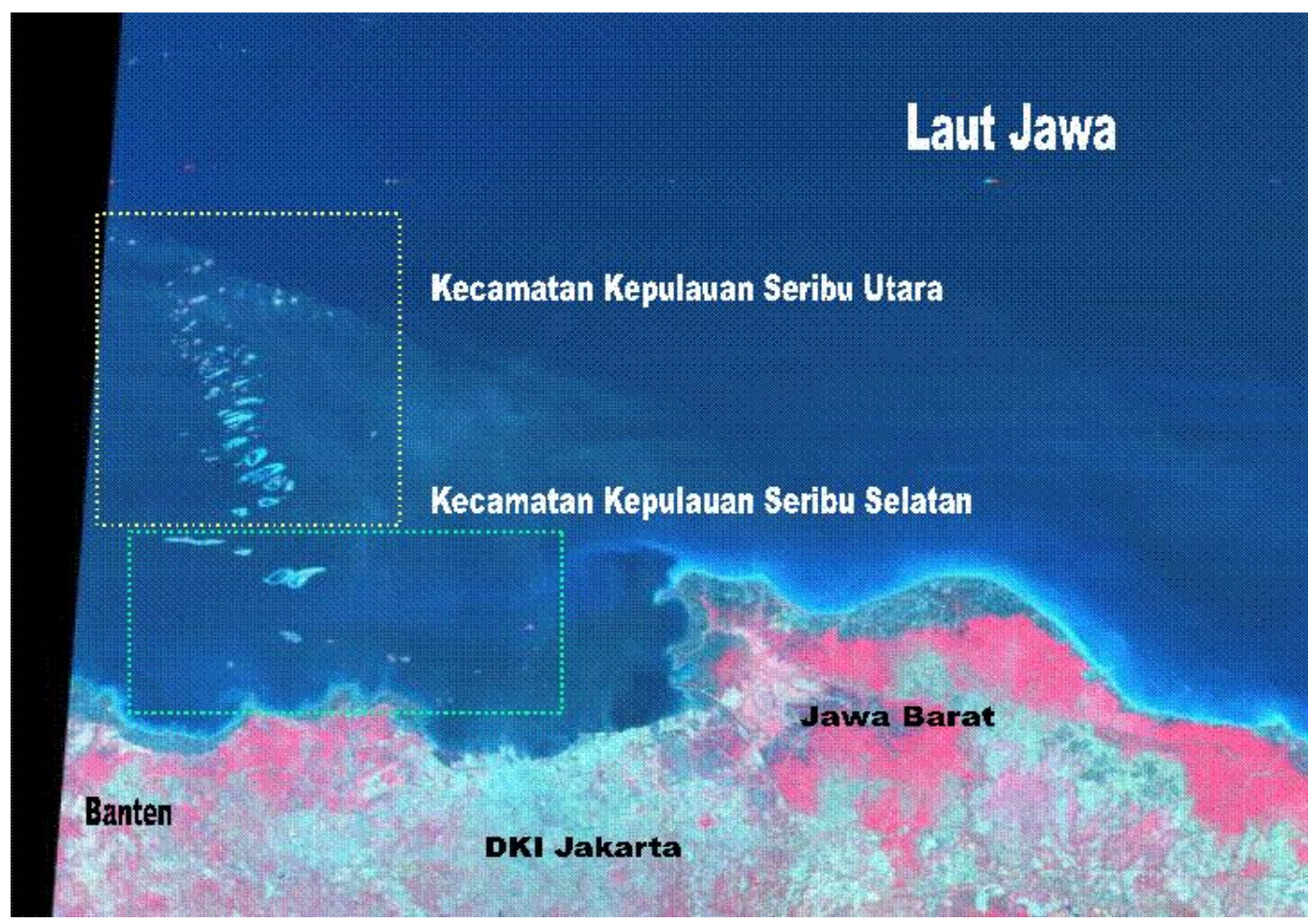

Gambar 2. Sebaran Pulau di Kepulauan Seribu 


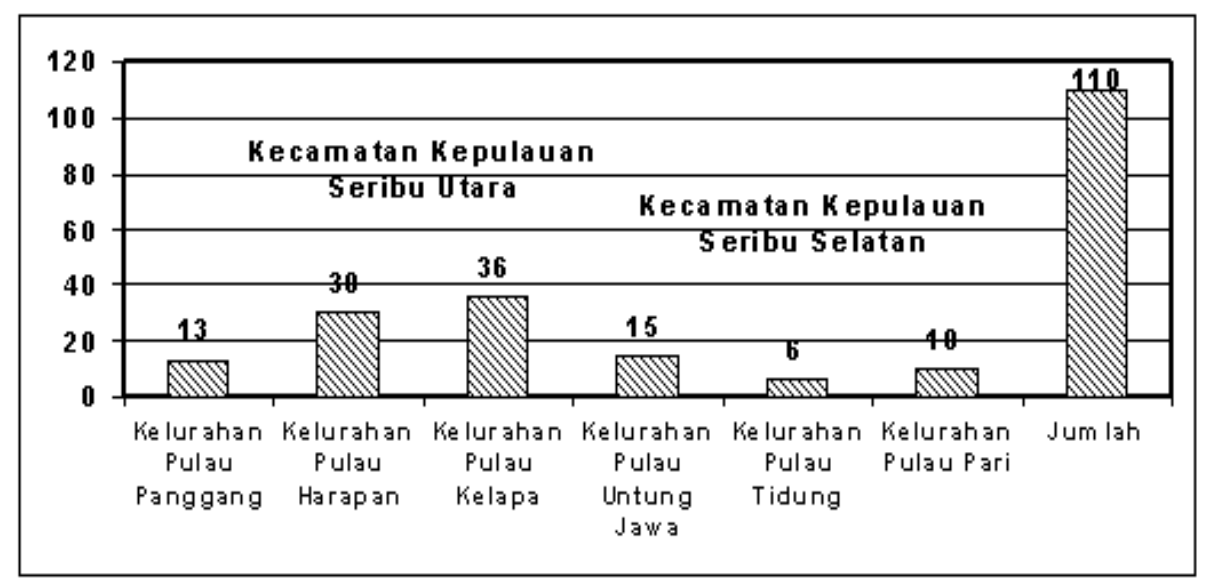

Sumber: Anonymous (1998)

Gambar 3. Jumlah Pulau di Kabupaten Kepulauan Seribu

Kecepatan arus di Pulau Pramuka, Pulau Panggang dan Pulau Karya pada waktu pasang purnama (spring tide) sebesar $5-49 \mathrm{~cm} /$ detik dengan arah bervariasi antara $3^{\circ}-35^{\circ}$. Di lokasi yang sama pada saat pasang perbani (neep tide) kecepatan arus tercatat sebesar 4 $38 \mathrm{~cm}$ /detik dengan arah bervariasi antara $16^{\circ}$ $35^{\circ}$.Kedudukan air tertinggi dan terendah di Kepulauan Seribu adalah $60 \mathrm{~cm}$ dan $50 \mathrm{~cm}$ di bawah duduk tengah. Rata-rata tunggang pasang perbani adalah $90 \mathrm{~cm}$ dan pasang mati $20 \mathrm{~cm}$. Tunggang pasang tahunan terbesar tercatat sebesar $110 \mathrm{~cm}$. Pengamatan di beberapa pulau di Kepulauan Seribu mencatat tinggi muka laut sebesar $101 \mathrm{~cm}$ pada skala Palem dan tinggi referensi kedalaman peta (chart datum) sebesar $65 \mathrm{~cm}$ di bawah muka laut ratarata ${ }^{9), 10), 12) .}$

\subsection{Kualitas Lingkungan Perairan}

Perairan Kepulauan Seribu yang berbatasan langsung dengan Teluk Jakarta memiliki resiko yang cukup tinggi terhadap bahaya pencemaran baik yang datang dari daratan maupun kegiatan pelayaran dari dan yang menuju pelabuhan Tanjung Priok di Jakarta Secara umum berdasarkan letak geografisnya, perairan Kepulauan Seribu paling tidak dapat dikelompokkan kedalam 3 kelompok besar yaitu perairan selatan yang berbatasan langsung dengan Teluk Jakarta (Pulau Untung Jawa, Pulau Lancang dan Pulau Pari), perairan bagian tengah (Pulau Tidung, Panggang, Pramuka, Semak Daun, Karang Cangkok dan Karang Bongkok), dan perairan bagian utara (Pulau Kelapa).

Hal ini terlihat pada gradasi tingkat kecerahan perairan seperti terlihat pada Tabel 2 . Perairan laut dari Teluk Jakarta sampai sekitar Pulau Bidadari dan Pulau Rambut termasuk kelompok selatan. Kelompok ini ditandai dengan keruhnya perairan laut serta relatif miskinnya biota yang berasosiasi dengan terumbu karang. Sedangkan kelompok tengah merupakan perairan laut sekitar Pulau Pari, Pulau Lancang, Pulau Semak Daun dan Pulau Karang Congkak. Perairan laut kelompok ini relatif lebih jernih dan kehidupan biotanya lebih bervariasi. Kelompok terakhir adalah perairan laut sekitar Pulau Genteng Besar, Pulau Kaya Angin, Pulau Bima, Pulau Belanda,sampai Pulau Pejaliran Barat. Kawasan ini merupakan kawasan paling jernih dan biotanya berasosiasi dengan terumbu karang dan lebih bervariasi.

Dengan mengacu kepada hasil penelitian IPB tahun 1997 dan hasil penelitian tahun 2004, terlihat bahwa kadar oksigen terlarut (DO), BOD dan COD, perairan Kepulauan Seribu juga tergradasi secara horizontal dimana konsentrasinya menurun seiring dengan semakin jauhnya dari Teluk Jakarta. Hal ini menunjukkan bahwa konsentrasi bahan organik di perairan Teluk Jakarta hingga Kepulauan Seribu juga tergradasi hampir secara proporsional berdasarkan jarak terhadap Teluk Jakarta seperti terlihat pada konsentrasi nitrogen terlarut (DIN) pada Tabel 2.

Dengan mengacu kepada nilai baku mutu berdasarkan SK Menteri KLH No. 02/MenKLH/I/1988 tertanggal 19 Januari 1988, kadar DO dan BOD masih masuk dalam kisaran layak guna, namun untuk nilai COD ternyata sudah melebihi ambang batas. Hal ini menunjukkan bahwa kualitas lingkungan perairan di Teluk Jakarta hingga Kepulauan Seribu sudah cukup kritis. Demikian halnya untuk kadar logam berat seperti $\mathrm{Cu}, \mathrm{Cd}$ dan air raksa $(\mathrm{Hg})$ telah melebihi ambang batas. Melihat kondisi yang demikian maka dalam perencanaan pengembangan budidaya laut perlu dilakukan secara hati-hati baik dalam pemilihan jenis komoditas maupun penyusunan tata ruang 
kegiatan budidayanya agar tidak hanya kepentingan produsen saja yang bisa terwakili, tetapi keamanan konsumen nantinya juga perlu diperhatikan dengan baik. Dengan perencanaan yang baik diharapkan kepercayaan konsumen akan keamanan produk budidaya yang dihasilkan dari perairan Kepulauan Seribu dapat meningkat, sehingga daya saing usahanyapun menjadi lebih baik.

\section{KESIMPULAN}

Secara umum kondisi perairan Kepulauan Seribu baik bagian selatan, tengah maupun utara dalam keadaan baik meskipun untuk parameter COD relatif lebih tinggi dari nilai baku mutu perairan yang ditentukan untuk mendukung budidaya. Untuk nilai kecerahan semakin ke selatan, nilai kecerahan semakin rendah, artinya perairan bagian selatan sangat dipengaruhi oleh kondisi perairan Teluk Jakarta dimana 13 sungai dengan tingkat kekeruhan yang cukup tinggi mengalir dan bermuara di Teluk Jakarta.

Demikian halnya dengan logam berat $\mathrm{Cd}$ dan $\mathrm{Pb}$ semakin ke selatan, konsentrasinya semakin tinggi. Dari kondisi yang demikian, maka kegiatan budidaya laut sebaiknya di arahkan di bagian tengah dan utara Kepulauan Seribu yang kulaitas perairannya relatif lebih baik dan berhadapan dengan laut terbuka sehingga daya dukung perairannya masih cukup baik.

Tabel 2. Kualitas Lingkungan Perairan di Kepulauan Seribu

\begin{tabular}{|c|c|c|c|c|c|c|c|}
\hline \multirow[b]{2}{*}{ Parameter } & \multicolumn{2}{|c|}{ Selatan } & \multicolumn{2}{|c|}{ Tengah } & \multicolumn{2}{|c|}{ Utara } & \multirow[b]{2}{*}{ Baku Mutu } \\
\hline & $1997^{\star}$ & 2004 & $1997^{\star}$ & 2004 & $1997^{\star}$ & 2004 & \\
\hline \multicolumn{8}{|l|}{ Fisika } \\
\hline Suhu ( C) & 29,5 & 29,4 & 29,1 & 29,4 & 29 & 30,3 & - \\
\hline Salinitas (ppm) & 32 & 33 & 32 & 30,1 & 32 & 32 & - \\
\hline Kecerahan (m) & 3,75 & $3-6$ & 5,5 & 6,6 & 8 & 13,6 & $>3$ \\
\hline Arus (cm/dtk) & 0,09 & - & 0,09 & 0,15 & 0,05 & - & - \\
\hline \multicolumn{8}{|l|}{ Kimia } \\
\hline $\mathrm{pH}$ & 7,5 & 8,3 & 7,5 & 7,3 & 7,5 & 6,6 & $6-9$ \\
\hline $\mathrm{DO}(\mathrm{mg} / \mathrm{l})$ & 6,4 & 6,8 & 5,7 & 7,2 & 4,4 & 7,0 & $>4$ \\
\hline $\mathrm{BOD}(\mathrm{mg} / \mathrm{l})$ & 2,7 & 3,4 & 1,9 & & 1,9 & & $<45$ \\
\hline $\mathrm{COD}(\mathrm{mg} / \mathrm{l})$ & 162,3 & 69,3 & 149,8 & 74,43 & 119,9 & 119,89 & $<80$ \\
\hline Silika (mg/l) & 0,011 & - & 0,009 & - & 0,01 & - & - \\
\hline Minyak (mg/l) & $<0,001$ & - & $<0,001$ & - & $<0,001$ & - & $<5$ \\
\hline DIN (mg/l) & 0,108 & 0,021 & 0,038 & 0,182 & 0,064 & 0,836 & $<1$ \\
\hline Fosfat (mg/l) & 0,010 & - & 0,018 & - & 0,018 & - & - \\
\hline Ammoniak (mg/l) & - & 0.24 & & 0,22 & & 0,25 & - \\
\hline \multicolumn{8}{|l|}{ Logam Berat } \\
\hline $\mathrm{Pb}(\mathrm{mg} / \mathrm{l})$ & 0,005 & 0,012 & 0,008 & 0,006 & 0,008 & 0,008 & $<0,01$ \\
\hline $\mathrm{Cu}(\mathrm{mg} / \mathrm{l})$ & 0,138 & 0,076 & 0,135 & 0,152 & 0,209 & 0,209 & $<0,06$ \\
\hline $\mathrm{Cd}(\mathrm{mg} / \mathrm{l})$ & 0,028 & 0,083 & 0,054 & 0,016 & 0,02 & 0,02 & $<0,01$ \\
\hline $\mathrm{Hg}(\mathrm{mg} / \mathrm{l})$ & 0,056 & 0.025 & 0,038 & 0,001 & 0,025 & 0,025 & $<0,003$ \\
\hline
\end{tabular}

Anonymous (1997 dan 1998)* 


\section{DAFTAR PUSTAKA}

1. Anna, S. (1999). Analysis beban pencemaran dan kapasitas asimilasi Teluk Jakarta. (Analysis of pollution load and assimilation capacity of Jakarta Bay). M.Sc. Thesis. Graduate school of Bogor Agricultural University. 99 pp.

2. Anonymous (1991). Pemantauan Teluk Jakarta, 1991. (Jakarta Bay Monitoring Report, 1991).Pemerintah Daerah Khusus Ibukota Jakarta. Kantor Pengkajian Perkotaan dan Lingkungan (KPPL). 124 pp.

3. Anonymous (1994). Pemantauan Teluk Jakarta 1993-1994. (Jakarta Bay Monitoring Report, 1993-1994). Pemerintah Daerah Khusus Ibukota Jakarta. Kantor Pengkajian Perkotaan dan Lingkungan (KPPL). 110 pp.

4. Anonymous (1997). Study of Jakarta Bay waters. Cooperation between office of City and Environment Studies, government of Jakarta City and Environmental Research Centre, Bogor Agricultural University. Bogor. 124 pp.

5. Anonymous (1998). The Study of the Using of Geographical Information System for Data Base ofJakarta Bay Waters. Office of City and Environment Studies, government of Jakarta City. 86pp.

6. Anonymous (1999). The Monitoring of Jakarta Bay, 1999. Office of City and Environment Studies, government of Jakarta City. 126 pp.
7. Anonymous (2002). Data Iklim dan Curah Hujan daerah DKI Jakarta dan sekitarnya. Badan Meteorologi Nasional. Jakarta.

8. Dahuri, R. 1994. Kebijakan Penataan Ruang Wilayah Pesisir, Menuju pemanfaatan Sumberdaya Kelautan, Indonesia. (Coastal Zone Zonation in the Indonesian Marine Resources Exploitations). Coastal Management in Tropical Asia, March, pp:1215.

9. Damar, A. (2003) : Effects of enrichment on nutrient dynamics, phytoplankton dynamics and productivity in Indonesian tropical waters : A comparison between Jakarta Bay, Lampung Bay and Semangka Bay. Dissertation. Christian-Albrecht University, Kiel.

10. llahude, A.G. (1995) : Sebaran suhu, salinitas, sigma-T, oksigen dan zat hara di perairan Teluk Jakarta. In Suyarso (Ed.). Atlas Oseanologi Teluk Jakarta. LIPI-P3O. Jakarta : 29-100.

11. Suyarso (1995) :. Lingkungan fisik pantai dan dasar perairan Teluk Jakarta. In Suyarso (Ed.). Atlas Oseanologi Teluk Jakarta. LIPIP3O. Jakarta, pp :21-28.

12. Setiawan, A. and M.R. Putri . (1998) : Study of current circulation in Jakarta Bay. Proceeding of the third International Symposium on Advanced and Aerospace Science and Technology in Indonesia, Jakarta. pp:803-810. 